УДК 615.322.074:547.466

\title{
АМИНОКИСЛОТНЫЙ СОСТАВ ЛЕКАРСТВЕННОГО РАСТИТЕЛЬНОГО СБОРА «ЛОРПОЛИФИТ» ДЛЯ ЛЕЧЕНИЯ ЗАБОЛЕВАНИЙ ВЕРХНИХ ДЫХАТЕЛЬНЫХ ПУТЕЙ
}

\author{
(C) У.Н. Буханова
}

\author{
Рязанский государственный медицинский университет им. И.П. Павлова, \\ ул. Есенина, 39, Рязань, 390023 (Россия), e-mail: pharm-tech@mail.ru
}

Обобщены сведения об аминокислотах, синтезируемых растениями, их функциях в аминокислотном обмене, фармакологической активности некоторых из них, особенно при формировании факторов противоинфекционной защиты организма при заболеваниях верхних дыхательных путей.

Актуализирована разработка точных методов качественного и количественного определения аминокислот в растительном сырье, а также необходимость нормирования общего содержания аминокислот при стандартизации лекарственных растительных сборов.

Методом ионообменной хроматографии с последующим детектированием продуктов реакции с нингидрином при двух длинах волн, с использованием аминокислотного анализатора, изучен качественный и количественный аминокислотный состав лекарственного растительного сбора «Лорполифит» (species «Lorpoliphytum») для лечения заболеваний верхних дыхательных путей. Сбор состоит из листьев подорожника (Plantago major L.), цветков ромашки (Chamomilla recutita L.), цветков календулы (Calendula officinalis L.), травы хвоща (Equisetum arvense L.), травы тысячелистника (Achillea millefolium L.), травы зверобоя (Hypericum perforatum L.), корневищ и корней девясила (Inula helenium L.). В исследуемом сборе «Лорполифит» установлено 19 аминокислот, из них: семь незаменимых, две условно заменимые (цистеин, тирозин), две частично заменимые (аргинин, гистидин). Общее содержание аминокислот в сборе составляет 9,42\%, среди которых преобладают глутаминовая кислота 13,49\%, аспарагиновая кислота 12,07\%, лейцин 8,47\%.

Ключевые слова: лекарственный растительный сбор, аминокислоты, аминокислотный анализатор, нингидриновая реакция, качественный, количественный состав.

\section{Введение}

Аминокислоты, синтезируемые растениями, можно подразделить на две категории: протеиногенные и непротеиногенные [1]. Двадцать протеиногенных аминокислот входят в состав белков, из них восемь аминокислот: лизин, валин, треонин, лейцин, изолейцин, метионин, триптофан, фенилаланин - являются «незаменимыми», т.е. организм человека не способен к их синтезу и должен получать их извне. Две аминокислоты - аргинин и гистидин - у взрослых очень медленно, но образуются в достаточных количествах. Поэтому их называют частично заменимыми. Тирозин и цистеин - условно заменимые аминокислоты, так как для их синтеза необходимы незаменимые аминокислоты фенилаланин и метионин соответственно [2]. Непротеиногенные аминокислоты (свыше 200 индивидуальных соединений) не входят в состав белков и обеспечивают уникальную особенность аминокислотного обмена у растений. Они обеспечивают азотный фонд (запас); транспортную форму азота по растению; легко подвергаются метаболизму и в случае необходимости снабжают растение $\mathrm{NH}_{4}{ }^{+}$для синтеза белков [1].

Лекарственные растительные сборы включают в себя различные группы биологически активных веществ (БАВ), в том числе и аминокислоты. Аминокислоты придают и другим БАВ легкоусваиваемую и безвредную форму, одновременно потенцируя их фармакологический эффект [3].

Установлено также, что сами $\alpha$-аминокислоты, наряду с другими БАВ, входящими в состав разного сырья, растительных сборов, обладают широким спектром фармакологической активности [4]. Они обеспечивают поддержку иммунной системы человека (лейцин, аргинин, аспарагиновая кислота). Лизин, треонин, фенилаланин, тирозин, аспарагин, глутамин, глицин, серин, аргинин являются исходными веществами

Буханова Ульяна Николаевна - ассистент кафедрь фармацевтической технологии, e-mail: pharm-tech@mail.ru для синтеза антител, ферментов и других веществ. Данные факты позволяют предполагать положительную роль аминокислот в формировании факто- 
ров и механизмов неспецифической и специфической противоинфекционной защиты организма при заболеваниях верхних дыхательных путей.

Разнообразные виды фармакологической активности аминокислот и лекарственных растительных препаратов на их основе актуализируют задачу современного химико-фармацевтического анализа - разработку точных и доступных методов количественного и качественного определения аминокислот в растительном сырье [5-10], а также в лекарственных растительных сборах [11]. Однако количественное содержание аминокислот в растениях подвержено изменению в результате влияния различных факторов (суточные, сезонные изменения, видовая, сортовая принадлежность растения, широта местности, фаза развития, сроки хранения, температура и др.), причем различия касаются не только суммарного содержания аминокислот, но и их качественного состава. Следовательно, для стандартизации лекарственного растительного сбора достаточно нормировать сумму свободных аминокислот [12].

В настоящее время существует ряд методов количественного определения аминокислот в лекарственном растительном сырье и экстракционных препаратах, основанных на реакции с нингидрином $[4,10$, 12], так как нингидрин специфичен к алифатическим или алициклическим первичным аминогруппам [2]. Широкое распространение в анализе аминокислот получили аминокислотные анализаторы [4].

Цель исследования - качественная и количественная оценка аминокислотного состава лекарственного растительного сбора «Лорполифит».

\section{Экспериментальная часть}

Объектом исследования являлся сбор «Лорполифит» - species «Lorpoliphytum» $[13,14]$ состоящий из листьев подорожника (Plantago major L.), цветков ромашки (Chamomilla recutita L.), цветков календулы (Calendula officinalis L.), травы хвоща (Equisetum arvense L.), травы тысячелистника (Achillea millefolium L.), травы зверобоя (Hypericum perforatum L.), корневищ и корней девясила (Inula helenium L.) - лекарственного растительного сырья, отвечающего требованиям ГФ ХІ издания [15].

Для, определения общего содержания аминокислот в исследуемом сборе был использован метод анализа, основанный на разделении аминокислот с помощью ионообменной хроматографии с последующим колориметрическим детектированием продуктов реакции с нингидрином при двух длинах волн (для первичных и вторичных аминов) [4]. Предварительно извлечение, полученное из образца сбора, подвергалось очистке от высокомолекулярных балластных веществ (пептидов) кислотным гидролизом с последующим центрифугированием. Результаты регистрировались в форме пиков абсорбции света элюатом из колонны по окончании цветной реакции. По наличию пиков в сравнении со стандартами, а также величинам пиков, прямо пропорциональным концентрациям данных веществ в извлечении, были определены качественный и количественный аминокислотный состав сбора «Лорполифит».

Аналитическую пробу сбора измельчали до размера частиц, проходящих сквозь сито с отверстиями размером 0,5 мм. Пробу массой 1,0 г (точная навеска) помещали в круглодонную колбу со шлифом, прибавляли 20 мл 70\% спирта этилового, взвешивали с точностью $\pm 0,01$ г и нагревали на водяной бане с обратным холодильником в течение 1 ч. Излечение затем охлаждали до комнатной температуры, взвешивали и при необходимости доводили $70 \%$ спиртом этиловым до первоначальной массы. Полученное извлечение фильтровали через бумажный фильтр. Первые 10 мл фильтрата отбрасывали. Из последующей порции фильтрата отбирали 50 мкл и упаривали досуха в вакуумном испарителе фирмы Servanta (США). Сухой остаток растворяли в 200 мкл $0,1 \mathrm{M}$ раствора кислоты хлористоводородной, нагревали на водяной бане в течение 15 мин при температуре $60^{\circ} \mathrm{C}$, перемешивали и центрифугировали в течение 3 мин при скорости 4000 оборотов в минуту. Для анализа использовали 50 мкл полученного гидролизата.

Аминокислотный анализ водорастворимых фракций проводили на аминокислотном анализаторе фирмы Hitachi, модель 835 , на стальной колонке $(0,4 \times 15$ см), заполненной катионообменной смолой марки 2619 (Hitachi Custom Jon-Exchange Resin). Разделение аминокислот проводилось в трех системах натрий цитратных буферных растворов: $0,18 \mathrm{H}-\mathrm{pH} 3,25 ; 0,3 \mathrm{H}-\mathrm{pH} 3,9 ; 1,6 \mathrm{H}-\mathrm{pH} 4,75$. Нингидриновый реактив готовили с использованием метилового эфира этиленгликоля. Цитратные буферные растворы подавали в колонку по стандартной программе со скоростью 32 мл/ч. Нингидриновый реактив подавали со скоростью 20 мл/час. После выхода из аналитической колонки разделенные аминокислоты смешивались с нингидриновым реактивом в смесительном блоке в соотношении $2: 1$. Реакция аминокислот с нингидриновым реактивом проходила за 4 мин при $100^{\circ} \mathrm{C}$ в реакционной бане. Колориметрическое измерение окрашенных комплексов, образующихся в результате реакции с нингидрином, проводилось непрерывно и одновременно при двух длинах волн. Первичные амины давали пурпурную окраску, оптическую плотность их измеряли при длине волны 570 нм, а вторичные (пролин и оксипролин) образовывали соединения желтой окраски, измерение проводили при длине волны 440 нм (рис.). 
Хроматограмма окрашенных комплексов разделенных аминокислот сбора «Лорполифит»

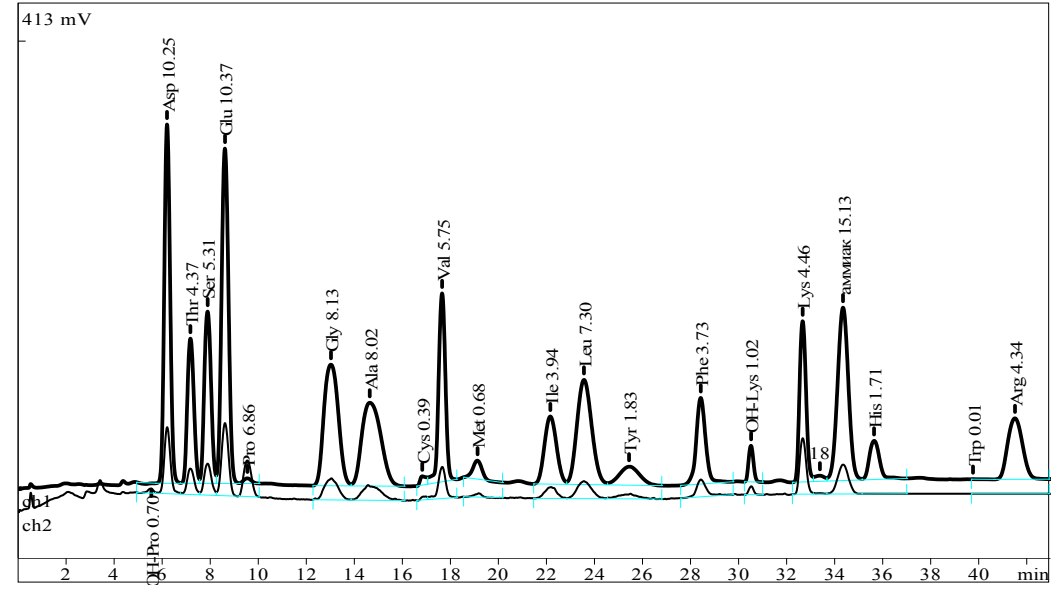

Оптическая плотность элюата автоматически регистрировалась on-line системой «МультиХром» для Windows (фирма «Амперсенд», Россия). Площади пиков идентифицированных аминокислот определялись автоматически. Количество каждой идентифицированной аминокислоты определяли в микрограммах в аликвоте, непосредственно использованной для анализа, а также в миллиграммах в грамме исходного образца сбора. Затем вычисляли количественное содержание обнаруженных аминокислот в исследуемом сборе (\%), а также долю аминокислоты от общего содержания (\%).

\section{Обсуждение результатов}

Результаты анализа аминокислотного состава лекарственного растительного сбора «Лорполифит» представлены в таблице.

Расчет суммы общего содержания аминокислот проведен на абсолютно сухую массу сбора «Лорполифит». Обнаружены и количественно определены 19 аминокислот, из них семь относятся к незаменимым. Наибольшее содержание в сборе отмечается для аминокислот глутаминовой, аспарагиновой, лейцина - 13,49; 12,$07 ; 8,47 \%$ соответственно. Минимальное содержание установлено для оксипролина и цистеина, равное $0,82 \%$; метионина $-0,89 \%$; оксилизина - 1,47\%.

\section{Выводы}

1. Изучен аминокислотный состав лекарственного растительного сбора «Лорполифит», включающего листья подорожника, цветки ромашки, цветки календулы, траву хвоща, траву тысячелистника, траву зверобоя, корневища и корни девясила, и установлено наличие 19 аминокислот, из них семь - незаменимых, две условно заменимых (цистеин, тирозин), две частично заменимых (аргинин, гистидин).

2. Общее содержание аминокислот исследуемого сбора составляет 9,42\% в расчете на абсолютно сухую массу сбора, в котором преобладают глутаминовая кислота 13,49\%, аспарагиновая кислота 12,07\%, лейцин $8,47 \%$.

\section{Список литературь}

1. Филипцова Г.Г., Смолич И.И.. Основы биохимии растений : курс лекций. Минск, 2014. С. 31-45.

2. Северин Е.С. Биохимия : учебник. М., 2004. 784 с.
Содержание аминокислот в сборе «Лорполифит»

\begin{tabular}{|c|c|c|}
\hline Аминокислота & $\begin{array}{c}\text { Общее содер- } \\
\text { жание амино- } \\
\text { кислот, \% }\end{array}$ & $\begin{array}{c}\text { Доля амино- } \\
\text { кислоты от } \\
\text { общего содер- } \\
\text { жания, \% }\end{array}$ \\
\hline Оксипролин & 0,08 & 0,82 \\
\hline Аспарагиновая кислота & 1,14 & 12,07 \\
\hline Треонин $^{*}$ & 0,43 & 4,61 \\
\hline Серин & 0,47 & 4,94 \\
\hline Глутаминовая кислота & 1,27 & 13,49 \\
\hline Пролин & 0,65 & 6,99 \\
\hline Глицин & 0,51 & 5,40 \\
\hline Аланин & 0,60 & 6,32 \\
\hline Цистеин ${ }^{* * *}$ & 0,08 & 0,82 \\
\hline Валин ${ }^{*}$ & 0,56 & 5,96 \\
\hline Метионин $^{*}$ & 0,08 & 0,89 \\
\hline Изолейцин ${ }^{*}$ & 0,43 & 4,57 \\
\hline Лейцин ${ }^{*}$ & 0,80 & 8,47 \\
\hline Тирозин $^{* * *}$ & 0,28 & 2,93 \\
\hline Фенилаланин ${ }^{*}$ & 0,51 & 5,46 \\
\hline Оксилизин & 0,14 & 1,47 \\
\hline Лизин ${ }^{*}$ & 0,54 & 5,78 \\
\hline Гистидин ${ }^{* *}$ & 0,22 & 2,35 \\
\hline Аргинин ${ }^{* *}$ & 0,63 & 6,69 \\
\hline Сумма & 9,42 & 100 \\
\hline
\end{tabular}

* - незаменимые аминокислоты; ${ }^{* *}$ - частично заменимые аминокислоты; ${ }^{* * *}$ - условно заменимые аминокислоты. 
3. Киселева Т.Л., Самылина И.А., Баратова Л.А. и др. Аминокислотный состав цветков фармакопейных и нефармакопейных видов Grataegus L. // Растительные ресурсы. 1989. Т. 25, вып. 1. С. 92-97.

4. Симонян А.В., Саламатов А.А., Покровская Ю.С., Аванесян А.А. Использование нингидриновой реакции для количественного определения $\alpha$-аминокислот в различных объектах: методические рекомендации. Волгоград, 2007. $106 \mathrm{c}$.

5. Асланова М.С., Магеррамов М.А. Физико-химические показатели и аминокислотный состав новых помологических сортов плодов граната // Химия растительного сырья. 2012. №1. С. 165-169.

6. Бубенчикова В.Н., Сухомлинов Ю.А. Лабазник шестилепестный: аминокислотный и минеральный состав // Фармация. 2005. №3. С. 9-11.

7. Наумова О.А., Попов Д.М. Определение аминокислот в плодах бархата амурского // Современные вопросы теории и практики лекарствоведения. Ярославль, 2007. С. 251-253.

8. Нгуен Тхи Ким Нган, Ермакова В.А. Аминокислотный состав ариземы единокровной // Фармация. 2014. №8. C. $10-12$.

9. Фурса Н.С., Белоусов М.В., Шкроботько П.Ю. и др. Анализ аминокислотного состава отдельных видов семейств бурачниковых, валериановых, вересковых, гвоздичных, грушанковых и яснотковых // Фармация. 2010. №4. C. 22-24.

10. Сафорзада Р.Ш., Халифаев Д.Р., Попов Д.М., Шарапов Ф.С. Исследование аминокислотного состава травы топинамбура, культивируемого в Таджикистане // Разработка и регистрация лекарственных средств. 2014. №3(8). C. 134-136

11. Селезенев Н.Г., Попов Д.М., Селезенев Г.Н. Аминокислотный состав урологического растительного сбора // Российский медико-биологический вестник им. академика И.П. Павлова. 2015. №3. С. 116-119.

12. Олешко Г.И., Ярыгина Т.И., Зорина Е.В., Решетникова М.Д. Разработка унифицированной методики количественного определения суммы свободных аминокислот в лекарственном растительном сырье и экстракционных препаратах // Фармация. 2011. №3. С.14-17.

13. Буханова У.Н., Попов Д.М., Селезенев Н.Г. Методика определения суммы фруктозанов и фруктозы в сборе «Лорполифит» // Фармация. 2013. №1. С. 22-24.

14. Буханова У.Н., Попов Д.М., Селезенев Н.Г. Разработка методик качественного и количественного определения суммы флавоноидов в сборе «Лорполифит» // Вопросы биологической, медицинской и фармацевтической химии. 2012. №3. С. 11-15.

15. Государственная фармакопея СССР: Вып. 2. Общие методы анализа. Лекарственное растительное сырье. М.: Медицина, 1989. 400 c.

Поступило в редакиию 5 августа 2015 г.

После переработки 17 декабря 2015 г. 
Bukhanova U.N. THE AMINO ACID COMPOSITION OF MEDICAL PLANT COLLECTION «LORPOLIPHYT» FOR THE TREATMENT OF THE UPPER AIR PASSAGES DISEASES

Ryazan State Medical University named after academician I.P. Pavlov, Esenina st., 39, Ryazan, 390023 (Russia), e-mail:pharm-tech@mail.ru

Information about the amino acids synthesized by plants, their functions in amino acid metabolism, pharmacological activity of some of them, especially in the formation of the factors of anti-infectious protection of the organism in diseases of the upper respiratory tract have been summarized.

The development of accurate methods of qualitative and quantitative determination of amino acids in plant material and the necessity of rationing the total content of amino acids in the standardization of medicinal plant collections was updated.

The qualitative and quantitative amino acid composition of medicinal plant collection «Lorpoliphyt» (species «Lorpoliphytum») for the treatment of diseases of the upper respiratory tract was studied by the method of ion exchange chromatography with subsequent detection of reaction products with ninhydrin at two wavelengths, using amino acid analyzer.

Collection consists of leaves of plantain (Plantago major L.), chamomile flowers (Chamomilla recutita L.), marigold flowers (Calendula officinalis L.), equisetum herbs (Equisetum arvense L.), yarrow herbs (Achillea millefolium L.), hypericum herbs (Hypericum perforatum L.), rhizomes and roots elecampane (Inula helenium L.). It was determined in the medicinal plant collection «Lorpoliphyt» of 19 amino acids, 7 of them - essential, 2 - conditionally nonessential (cysteine, tyrosine), 2 - partially replaceable (arginine, histidine). The total content of amino acids in the medicinal plant collection «Lorpoliphyt» is $9,42 \%$, which are dominated $13,49 \%$ glutamic acid, aspartic acid $12,07 \%$, leucine $8,47 \%$. composition.

Keywords: medicinal plant collection, amino acids, amino acid analyzer, ninhydrin reaction, qualitative, quantitative

\section{References}

1. Filipcova G.G., Smolich I.I. Osnovy biohimii rastenij: kurs lekcij. [Fundamentals of Plant Biochemistry: lectures]. Minsk, 2014, pp. 31-45. (in Russ.).

2. Severin E.S. Biohimija: uchebnik. [Biochemistry: textbook]. Moscow, 2004, 784 p. (in Russ.).

3. Kiseleva T.L., Samylina I.A., Baratova L.A. i dr. Rastitel'nye resursy, 1989, vol. 25, no. 1, pp. 92-97. (in Russ.).

4. Simonjan A.V., Salamatov A.A., Pokrovskaja Ju.S., Avanesjan A.A. Ispol'zovanie ningidrinovoj reakcii dlja kolichestvennogo opredelenija $\alpha$-aminokislot $v$ razlichny obektah: metodicheskie rekomendacii. [Using the ninhydrin test for the quantitative determination of $\alpha$-amino acids in various objects: guidelines]. Volgograd, 2007, $106 \mathrm{p}$. (in Russ.).

5. Aslanova M.S., Magerramov M.A. Himija rastitel'nogo syr'ja, 2012, no. 1, pp. 165-169. (in Russ.).

6. Bubenchikova V.N., Suhomlinov Ju.A. Farmacija, 2005, no. 3, pp. 9-11. (in Russ.).

7. Naumova O.A., Popov D.M. Sovremennye voprosy teorii i praktiki lekarstvovedenija. Jaroslavl', 2007, pp. $251-253$. (in Russ.).

8. Nguen Thi Kim Ngan, Ermakova V.A. Farmacija, 2014, no. 8, pp. 10-12. (in Russ.).

9. Fursa N.S., Belousov M.V., Shkrobot'ko P.Ju. i dr. Farmacija, 2010, no. 4, pp. 22-24. (in Russ.).

10. Saforzada R.Sh., Halifaev D.R., Popov D.M., Sharapov F.S. Razrabotka i registracija lekarstvennyh sredstv, 2014, no. 3(8), pp. 134-136. (in Russ.).

11. Selezenev N.G., Popov D.M., Selezenev G.N. Rossijskij mediko-biologicheskij vestnik im. akademika I.P. Pavlova. 2015, no. 3, pp. 116-119. (in Russ.).

12. Oleshko G.I., Jarygina T.I., Zorina E.V., Reshetnikova M.D. Farmacija, 2011, no. 3, pp.14-17. (in Russ.).

13. Buhanova U.N., Popov D.M., Selezenev N.G. Farmacija, 2013, no. 1, pp. 22-24. (in Russ.).

14. Buhanova U.N., Popov D.M., Selezenev N.G. Voprosy biologicheskoj, medicinskoj i farmacevticheskoj himii, 2012, no. 3, pp. 11-15. (in Russ.).

15. Gosudarstvennaja farmakopeja SSSR: Vyp. 2. Obshhie metody analiza. Lekarstvennoe rastitel'noe syr'e. [The State pharmacopoeia of the USSR: Vol. 2. General methods of analysis. Medicinal herbs]. Moscow, 1989, 400 p. (in Russ.). 
